\title{
Immunoassays for Affinity, Avidity and Competition: Methods to Evaluate Monoclonal (and Polyclonal) Antibodies Useful Assays in Development of New Antibodies, Better Understanding of Commercial Antibodies: Their Usefulness in Specific Aims of Research
}

\author{
Anita Lewis Antes \\ New Jersey Medical School/Rutgers University/Newark NJ \\ E-mail:antesan@njms.rutgers.edu \\ Received 20 October 2015; Accepted 25 October 2015; \\ Publication 3 February 2016
}

Keywords: ELISA (enzyme linked immune absorbant assay), specificity, sensitivity, affinity, monoclonal antibody, hybridoma, epitope.

Enzyme-linked immunosorbent assay (ELISA) remains the most common method to identify clones of cells during the development of monoclonal antibodies. This technique is convenient for the rapid screening of large numbers of clones, subsequent to the fusion of splenocytes of immunized mice or rabbits with immortal myeloma cells. In general, when screening for the production of the desired antibody, an antibody to the target protein or an antibody from another host is generally unavailable. Thus, the standard test measures reactivity of attachment passively to the target antigen, and reporting of that attachment using a secondary antibody reporter (sandwich assay). Slightly better is the ELISA, which reacts the monoclonal within the

International Journal of Translational Science, Vol. 2016, 1-4.

doi: 10.13052/ijts2246-8765.2016.001

(c) 2016 River Publishers. All rights reserved. 


\section{A. L. Antes}

cell culture (supernatant) with the antigen and then applies the mix to plates coated with an antibody against the target, but from another host species. In this way, the ability of the test clones to capture the target may be examined. This method is required when preparing antibodies for immunoprecipitation.

The sandwich assay may leave the investigator with as many as 100 or more prospective clones to further characterize. To identify clones for further investigation of the target antigen, cell supernatants may be too dilute. Thus, the expansion of this enormous number of clones for subsequent purification of the antibodies would be a daunting task. Here we offer EIA-based assays which simplify the process of excluding the majority of clones which will not serve the researcher's requirements. All the assays can be done from a single stock of each clone of as little as $2 \mathrm{ml}$ volume.

\section{Materials and Methods}

\subsection{Hybridoma Cells Propagation of Supernatants}

Single cell subclones of candidate hybridomas are seeded at $1 \times 10^{5}$ cells/ $60 \mathrm{~mm}$ dish (or $2 \times 10^{6}$ cells $/ 100 \mathrm{~mm}$ dish). Cell supernatants are collected 4-5 days post-seeding and then clarified by centrifugation at $5000 \mathrm{rpm}$ for 5 minutes at $4{ }^{\circ} \mathrm{C}$. This is followed by filtering through a 0.2 micron sterile cellulose acetate membrane syringe filter. Supernatants should be stored at $4^{\circ} \mathrm{C}$.

\subsection{ELISA based Characterization of Monoclonal Antibody Epitopes}

\subsubsection{Affinity assay}

Greiner flat bottom, non-tissue culture 96-well plates are coated overnight with $50-100 \mathrm{ng} /$ well of the antigen. The plates are incubated overnight at $4{ }^{\circ} \mathrm{C}$. Row A will not be coated and will represent the evaluation of non-specific binding.

Plate surfaces are blocked with $100 \mu \mathrm{l} /$ well PBS/0.1\% Tween 20/1\% BSA (Sigma), 1 hour at room temperature.

After thorough wash with PBS/Tween 20,50 $\mu$ l diluent (PBS) is added to wells $\mathrm{C} 1$ through $\mathrm{H} 12 ; 100 \mu \mathrm{l}$ of filtered cell supernatant is added to row B wells in triplicates. Using a 12 channel pipettor, $50 \mu \mathrm{l}$ from row B is added to row $\mathrm{C}$, mixed, and the process continued through row $\mathrm{H}$, where the last $50 \mu \mathrm{l}$ is discarded after diluting with the samples from row G. Note: $50 \mu \mathrm{l}$ of cell supernatant, neat (undiluted), is also added to row A. 
Incubation is performed at RT for 2 hours, followed by thorough wash with PBS/Tween. Secondary antibody Goat anti-Mouse H+L IgG conjugated to alkaline phosphatase (Jackson Immunoresearch) is applied at $<0.5 \mu \mathrm{g} / \mathrm{well}$, incubated at room temperature for 40 minutes. After thorough washing, the substrate is added to each well and the plates are read for alkaline phosphatase on the plate reader using a $405 \mathrm{~nm}$ filter.

\subsubsection{Avidity assay}

Sample plates are prepared as follows: $50 \mu \mathrm{l}$ of diluent is added to all wells of a blank plate, except row A, into which $100 \mu$ l of target antigen (0.05-0.1 $\mathrm{ng} / \mu \mathrm{l})$ is placed.

Using a 12 channel pipettor, $50 \mu \mathrm{l}$ from row $\mathrm{A}$ is mixed with the diluent in row $\mathrm{B}$. The process is repeated up to row $\mathrm{H}$, where the final $50 \mu \mathrm{l}$ is removed and discarded. As previously described, plates are incubated overnight at $4{ }^{\circ} \mathrm{C}$, then blocked, and washed. Cell supernatants, in triplicate, undiluted, are added, $100 \mu \mathrm{l} /$ well, and then incubated as described in the affinity assay. Average absorbance values are plotted vs antigen dilution value, and cell supernantants displaying linear response to the lowest antigen value are deemed most avid.

\subsubsection{Competition assay}

Results from the Affinity Assay are used to determine the concentration of each cell supernatants to be used in the experiment. Plotting the absorbance values vs the dilution value of the supernantants, the $50 \%$ point will be determined for each sample. Each of the cell supernatants will be diluted to reflect the concentration of $50 \%$ absorbance value. The assay will be performed in triplicate. First, a replicate plate with the diluted supernatants is prepared by dispensing $50 \mu \mathrm{l}$ each of two supernatants (a pair) into the wells of a blank plate. The samples are then transferred to a standard coated plate, and the ELISA proceeded as described previously. Absorbance values of paired supernatants equal or greater than their $50 \%$ value alone suggested antibodies which could be used in capture reporter assays.

\section{References}

[1] Lequin, R. M. (2005). "Enzyme Immunoassay (EIA)/Enzyme-Linked Immunosorbent Assay (ELISA)". Clinical Chemistry 51 (12): 2415-8.

[2] Engvall, Eva; Perlmann, Peter (1971). "Enzyme-linked immunosorbent assay (ELISA) quantitative assay of immunoglobulin G". Immunochemistry 8 (9): 871-4. 
[3] Van Weemen, B.K.; Schuurs, A.H.W.M. (1971). "Immunoassay using antigen-enzyme conjugates". FEBS Letters 15 (3): 232-236.

[4] Kragstrup, Tue W; Vorup-Jensen, Thomas; Deleuran, Bent; Hvid, Malene (2013). "A simple set of validation steps identifies and removes false results in a sandwich enzyme-linked immunosorbent assay caused by anti-animal IgG antibodies in plasma from arthritis patients". SpringerPlus 2 (1): 263.

\section{Biography}

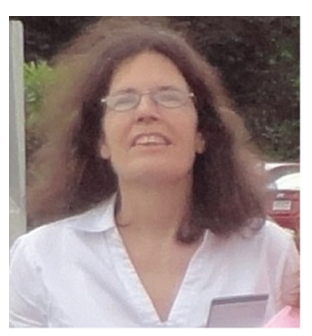

A. L. Antes Research Teaching Specialist II, Research Teaching Specialist III, UMDNJ, Newark, New Jersey, USA.

Inventions: Property of the New York State Research Foundation Licensed non-exclusively to Oncogene Science.

R-264: "Monoclonal Antibodies to the Rouse Sarcoma Virus Transforming Protein", R-567: "Hybridoma AZA2E8" Epstein-Barr Nuclear Antigen Monoclonal Antibody. 